This is an electronic reprint of the original article. This reprint may differ from the original in pagination and typographic detail.

Author(s): Hänninen, Mikko M.; Peuronen, Anssi; Tuononen, Heikki

Title: Do Extremely Bent Allenes Exist?

Year: $\quad 2009$

Version:

Please cite the original version:

Hänninen, M. M., Peuronen, A., \& Tuononen, H. (2009). Do Extremely Bent Allenes Exist?. Chemistry - A European Journal, 15(30), 7287-7291.

https://doi.org/10.1002/chem.200900928

All material supplied via JYX is protected by copyright and other intellectual property rights, and duplication or sale of all or part of any of the repository collections is not permitted, except that material may be duplicated by you for your research use or educational purposes in electronic or print form. You must obtain permission for any other use. Electronic or print copies may not be offered, whether for sale or otherwise to anyone who is not an authorised user. 


\title{
Do extremely bent allenes exist?
}

\author{
Mikko M. Hänninen, Anssi Peuronen and Heikki M. Tuononen*[a]
}

\author{
Dedicated to Professor Ronald J. Gillespie on the occasion of his $85^{\text {th }}$ birthday.
}

In a recently published Communication, Bertrand et al. reported the synthesis and ligand properties of a stable five-membered ring allene 1b containing only first-row main group atoms. ${ }^{[1]} \mathrm{A}$ correspondence was published soon after by Christl and Engels, who, based on theoretical data for related six-membered cyclic allenes, argued that the compound in question should not be represented as an allene 1' but rather as a zwitterion 1'" [2a] Bertrand et al. issued a response to the critique, defending their point of view with selected experimental and theoretical evidence as well as invoking author's right to name a compound. ${ }^{[2 b]}$ In the current contribution, we present detailed quantum chemical analyses performed for a set of related molecules, as well as for the model system 1a, which show how the controversy can be resolved in favor of both parties. In addition, the chemistry of $\mathrm{N}$ heterocyclic carbenes (NHCs) is discussed through the prism of the reported findings.

$$
\begin{aligned}
& \text { 2a: } \mathrm{R}=\mathrm{H} ; \mathrm{R}^{\prime}=\mathrm{H} \\
& \text { 2a: } \mathrm{R}=\mathrm{H} \\
& \text { Mikko M. Hänninen, Anssi Peuronen and Adjunct Professor Dr. Heikki M. } \\
& \text { Tuononen } \\
& \text { Department of Chemistry } \\
& \text { University of Jyväskylä } \\
& \text { PO Box 35, Fy-40014, Finland } \\
& \text { Tel.: (+358)14-260-2618 } \\
& \text { Fax: (+358)14-260-1501 } \\
& \text { E-mail: heikki.m.tuononen@jyu.fi }
\end{aligned}
$$

The equilibrium geometry of the parent allene $\mathbf{2 a}$ is linear with orthogonal arrangement of hydrogen atoms $\left(D_{2 \mathrm{~d}}\right) \cdot{ }^{[3]} \mathrm{It}$ is well known that artificial bending of the molecular framework brings the point group down to $C_{2}$ and lifts the degeneracy of the frontier orbitals. ${ }^{[4]}$ The HOMO retains its $\pi$-type shape with respect to the plane formed by the $\mathrm{C}-\mathrm{C}-\mathrm{C}$ backbone but an increasing amount of s-character is introduced to HOMO-1 as the bond angle becomes more acute. When extremely bent, the HOMO-1 becomes a lone pair orbital localized at the central carbon atom (Figure 1) in agreement with simple hybridization (valence bond) theory based arguments. Hence, bent acyclic singlet allenes eventually adopt an electronic structure which is most conveniently represented using the extended Lewis formula 2' i.e. one $\sigma$-symmetric lone pair and two delocalized $\pi$-electrons. ${ }^{[5]}$ This transformation is illustrated perhaps the best by visualizing the electron localization function (ELF) ${ }^{[6]}$ calculated for $\mathbf{2 a}$ at different bond angles (Figure 1), which reveals a monosynaptic, lone pair, valence basin $\mathrm{V}\left(\mathrm{C}_{2}\right)$ at angles below $120^{\circ} .^{[7]}$ The above conclusion is further supported by atoms in molecules (AIM) analysis ${ }^{[8]}$ as well as calculated atomic charges, which reveal an electroneutral central carbon atom with one $(3,-3)$ critical point indicative of a single non-bonded pair of electrons.

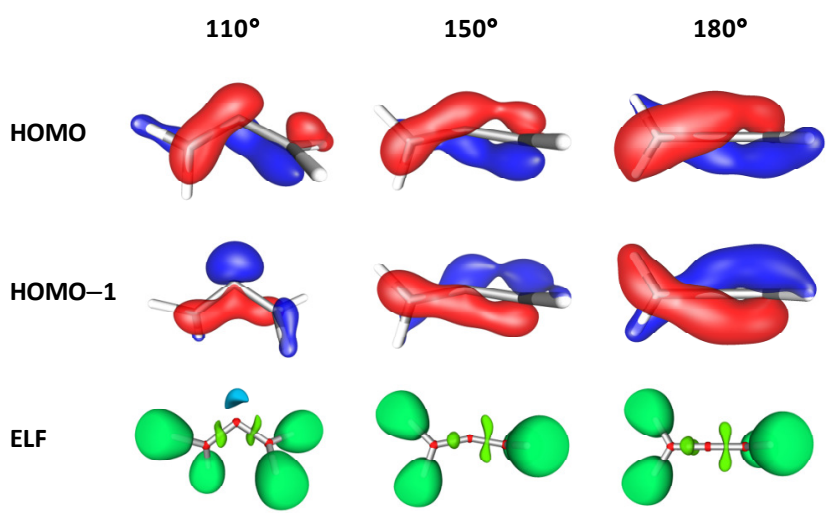

Figure 1. Frontier molecular orbitals and electron localization function of $\mathbf{2 a}$ at different bond angles.

The change in the electronic structure of allenes upon bending should by no means be limited to acyclic species. In cyclic systems the allene framework is naturally enforced to deform as the size of the ring becomes smaller. ${ }^{[4]}$ The calculated $\mathrm{C}_{1}-\mathrm{C}_{2}-\mathrm{C}_{3}$ 
bond angle for 1,2-cycloheptene 3 and -hexene $\mathbf{4}$ is $149^{\circ}$ and $133^{\circ}$, respectively. The electronic structures of these ring systems are clearly of allene-type as neither MO nor ELF/AIM analysis shows any indication of a distinct $\sigma$-lone pair at the central carbon atom (Figure 2). For 1,2-cyclopentadiene 5, the bond angle drops down to $109^{\circ}$. Consequently, the molecule adopts an electronic structure akin to 2' and it cannot be considered a classical allene as has been suggested before. ${ }^{[2,4,9]}$ However, it turns out that $\mathbf{5}$ has sufficient singlet diradical character that it cannot be described with only one closed-shell Kohn-Sham determinant. ${ }^{[4 b, 9]}$ Brokensymmetry density functional theory (DFT) and complete active space (CAS) calculations show that the diradical character in $\mathbf{5}$ leads to transfer of electron density from HOMO-1 and HOMO to LUMO. ${ }^{[10]}$ This is also borne out by ELF analysis (Figure 2c) which shows that the $\mathrm{V}\left(\mathrm{C}_{2}\right)$ lone pair basin population diminishes roughly by half of an electron when the diradical character is appropriately treated in calculations. Nevertheless, the electronic structure of $\mathbf{5}$ can still be represented most conveniently using the extended Lewis formula $\mathbf{5}$ '.<smiles>C1=CCCCCC1</smiles>

3<smiles>C1=CCCCC1</smiles>

4

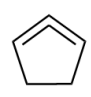

5

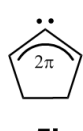

5' a)

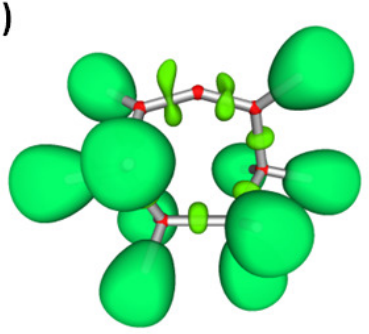

c)

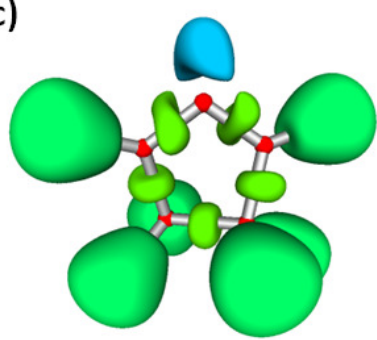

b)

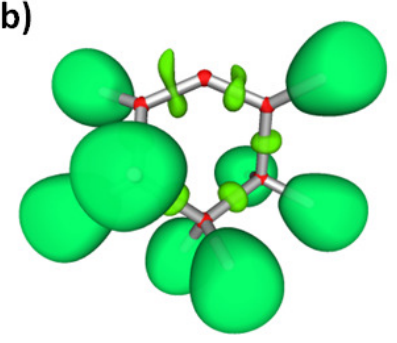

type bonding character within $\mathrm{C}-\mathrm{C}, \mathrm{C}-\mathrm{N}$ and $\mathrm{C}-\mathrm{O}$ linkages, in agreement with the determined bond lengths, but the non-planar nature of the molecule prevents true cyclic electron delocalization. The calculated nucleus independent chemical shift ${ }^{[11]} \operatorname{NICS}(1)_{z z}$ index for 1a is $-15 \mathrm{ppm}$. In comparison, the NICS $(1)_{z z}$ index of cyclopentadiene, a true $6 \pi$-electron aromatic, is $-34 \mathrm{ppm}$. We note that if the $-\mathrm{OH}$ groups in $\mathbf{1 a}$ are replaced by hydrogen atoms, the HOMO $\rightarrow$ LUMO gap decreases to $3.9 \mathrm{eV}$ and the molecule adopts a near-planar geometry. The NICS $(1)_{z z}$ index calculated for such species is $-32 \mathrm{ppm}$, indicating a significant change in the electronic structure towards aromaticity. These results confirm that exocyclic substituents play a more important role to the stability of $\mathbf{1}$ than cyclic electron delocalization.
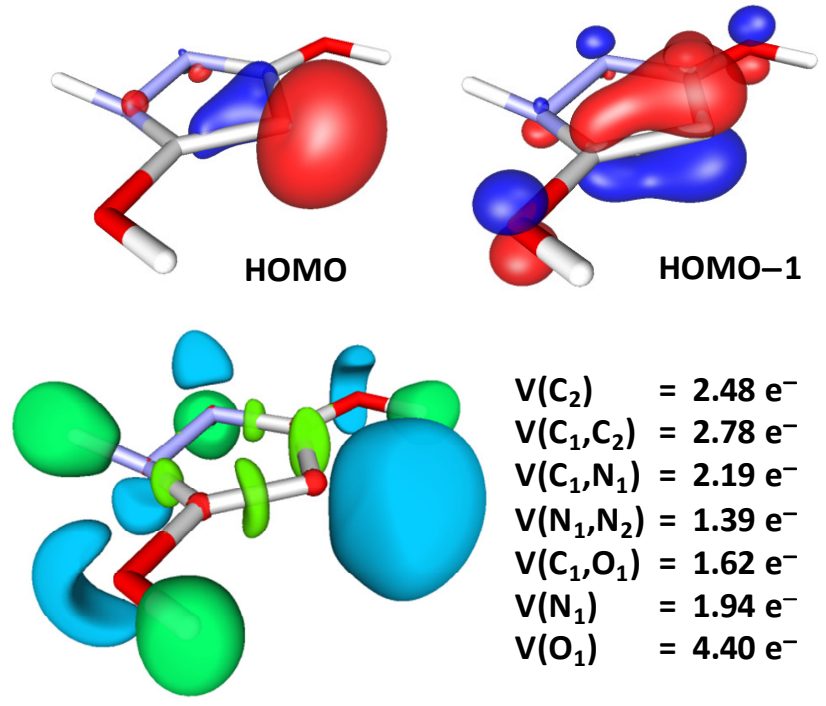

Figure 3. Frontier molecular orbitals (top) and electron localization function (bottom) of $1 \mathrm{a}$.

The IUPAC Gold Book ${ }^{[12]}$ defines allenes as "hydrocarbons (and by extension, derivatives formed by substitution) having two double bonds from one carbon atom to two others, $\mathrm{R}_{2} \mathrm{C}=\mathrm{C}=\mathrm{CR}_{2}$ ". In light of results presented herein, an extremely bent allene appears to be an oxymoron. On the other hand, NHCs are widely accepted as carbenes even though their electronic structure differs from the IUPAC definition. ${ }^{[12]}$ In addition, as far as the general electronic structure is concerned, $\mathbf{1 b}$ is as close to an extremely bent allene $\mathbf{5}$ as can possibly be. Thus, considering $\mathbf{1 b}$ formally as an allene is convenient since it is derived from allenes. However, representing its electronic structure with either 1' or 1' is misleading as they both point to inaccurate ground state configuration. Based on the theoretical analyses presented herein, a more appropriate representation of the electronic structure of $\mathbf{1 b}$ is given by the extended Lewis formula 1',', analogous to 2' and 5'. This is also the best single Lewis-type structure assigned to 1a by natural bond orbital (NBO) analysis. ${ }^{[13]}$ Alternatively, 1", can be decomposed to two localized, zwitterionic, Lewis structures. However, the main contribution comes from $\mathrm{C}^{+}-\mathrm{C}^{-}=\mathrm{C} \leftrightarrow$ $\mathrm{C}=\mathrm{C}^{-}-\mathrm{C}^{+}$resonance as evidenced by both calculated atomic charges and NBO analyses using Lewis-structures restricted to 2center-2-electron bonds. Nevertheless, it should be remembered that 1", only represents the leading contribution in the wave function and a more accurate representation of reality requires the structure to be drawn as a resonance hybrid. ${ }^{[14]}$

In light of the true electronic structure of $\mathbf{1 b}$, its chemical properties appear anything but peculiar. ${ }^{[1]}$ In particular, it can be 
readily explained why it coordinates to metal centers using $\eta^{1}$ mode instead of $\eta^{2}$ typically observed for allenes. ${ }^{[3]}$ In many respects $\mathbf{1 b}$ resembles NHCs, ${ }^{[15]}$ for which zwitterionic Lewis structures can also be drawn, and can therefore be considered a carbenoid i.e. a complexed carbene-like entity that displays the reactivity characteristics of carbenes. ${ }^{[12]}$ However, the shape of the HOMO-1 orbital implies that $\pi$-electrons might be more readily accessible for bond formation in $\mathbf{1 b}$ than in NHCs. Hence, as has been suggested before, ${ }^{[1,2 b]} \mathbf{1 b}$ could display hidden divalent carbon $(0)$ character akin to carbodicarbenes $\mathbf{6}^{[16-18]}$
6<smiles>[R]N1C=CNC1=C=c1cn[R][nH]1</smiles><smiles>[R9][P+]#[C-]</smiles>

7
Carbodicarbenes can formally be considered bent allenes but detailed $\mathrm{AIM}^{[16 \mathrm{~b}]}$ and molecular electrostatic potential (MESP) ${ }^{[19]}$ analyses have revealed one $(3,-3)$ critical point indicative of (at least) one non-bonded pair of electrons located at the central carbon atom. ${ }^{[20]}$ However, strong Lewis acids can bring to fore their divalent carbon(0) nature. ${ }^{[16,18]}$ The chemical behavior of carbodicarbenes can be rationalized by the shape of their $\sigma$ - and $\pi$-type frontier MOs which are localized on the central carbon atom. ${ }^{[16]}$ Accordingly, push-push substitution in $\mathbf{6}$ induces a flow of electrons to the central carbon atom in an analogous manner to what artificial bending does for 2a. ${ }^{[22]}$ Consequently, the electronic structure of carbodicarbenes resides in between that of tetravalent carbon( $(0)$ and divalent carbon( 0$)$, though much closer to the latter, and only a modest energetic perturbation is required to transform their bonding characteristics. ${ }^{[16,18]}$ These results can be contrasted to data reported for carbodiphosphoranes 7 which, even as isolated molecules, appear as true divalent carbon( 0 ) compounds. ${ }^{[19,23,24]}$

A comparison of $\mathbf{1 a}$ to data reported for imidazol-2ylidene ${ }^{[16,25]}$ and carbodicarbenes ${ }^{[16]}$ reveals that, as an isolated entity, its electronic structure has more in common with the former. Hence, it can be expected that systems 1 function as two electron donors unless extremely strong electrophiles are used. In good agreement, theoretical calculations demonstrate that the first and second proton affinities of $\mathbf{1 a}$ are 1200 and $370 \mathrm{~kJ} \mathrm{~mol}^{-1}$, respectively ( $c f$. 1180 and $634 \mathrm{~kJ} \mathrm{~mol}^{-1}$ for $N$-Me substituted carbodicarbene and 1064 and $200 \mathrm{~kJ} \mathrm{~mol}^{-1}$ for parent NHC). ${ }^{[16 \mathrm{~b}]}$ Consequently, coordination of two $\mathrm{BH}_{3}$ ligands to $\mathbf{1 a}$ does not give a chemically stable species but leads to a transition state with respect to ligand exchange. However, the aluminum analogue 1a. $\left(\mathrm{AlH}_{3}\right)_{2}$ is a stable minimum with a calculated dissociation energy of approximately $50 \mathrm{~kJ} \mathrm{~mol}^{-1}$ with respect to $\mathbf{1 a} \cdot \mathrm{AlH}_{3}$ and $\mathrm{AlH}_{3}$. We note that real-life synthetic attempts towards $\mathbf{1} \mathbf{b} \cdot\left(\mathrm{AlH}_{3}\right)_{2}$, or any related systems, might be thwarted by e.g. the steric bulk of the substituents attached to oxygen atoms.

In summary, the results reported herein unambiguously demonstrate that extremely bent allenes, be they cyclic or acyclic, only bear a formal relationship with classical allenes. In particular, the five-membered ring systems $\mathbf{1}$ and $\mathbf{5}$ both posses a lone pair of electrons at the $\mathrm{C}_{2}$ carbon. It has been demonstrated that $\mathbf{1 b}$ acts as a strong $\sigma$-donor and thus shares many of the properties associated with carbenes. Hence, it is best described as a carbenoid. Depending on the emphasis, its electronic structure can be represented using either localized (zwitterioinic) or delocalized (carbene-like) Lewis structures. Thus, $\mathbf{1 b}$ bridges the gap between classical allenes and carbodicarbenes. When combined with extremely electrophilic metal fragments, the $\pi$-electrons in $\mathbf{1 b}$ can, at least in principle, be used for bonding and the ligand acts as a four electron donor. By analogy, it seems reasonable that, via appropriate modification of the electronic structure, one could design NHCs that could be classified as carbenes as isolated species, but would nevertheless display bonding to electrophilic metals using four electrons. Similar behavior has already been demonstrated for the heavier group 14 analogues of NHCs which contain a bipyridyl backbone. ${ }^{[25,26]}$ Surprisingly, theoretical calculations show that $\mathrm{AlH}_{3}$ forms a marginally stable $(15 \mathrm{~kJ}$ $\mathrm{mol}^{-1}$ ) 2:1 complex even with the parent imidazol-2-ylidene. Such systems are currently under active computational investigation by our group.

\section{Experimental Section}

The theoretical calculations were performed with Turbomole 5.10 $0^{[27]}$ and Gaussian 03 program packages. ${ }^{[28]}$ The geometries were optimized using density functional theory. A combination of B3LYP hybrid functional ${ }^{[29]}$ and Ahlrich's def2-TZVP basis sets ${ }^{[30]}$ was employed. The nature of all stationary points found was assessed by performing frequency analyses. Complete active space calculations for 5 used the DFT optimized geometry and an active space in which four highest electrons and orbitals were correlated i.e. CAS $(4,4)$. NICS values were determined at $1 \AA$ above the molecular plane and only the component of the magnetic shielding tensor perpendicular to the plane (zz) was used in the analysis. ELF, AIM and NBO analyses were performed with programs TopMod, ${ }^{[31]}$ Bubble $^{[32]}$ and NBO 5.G, ${ }^{[33]}$ respectively, whereas program gOpenMol was used for all visualizations. ${ }^{[34]}$

\section{Acknowledgements}

We are grateful to the Academy of Finland and University of Jyväskylä for financial support of this research.

[1] V. Lavallo, C. A. Dyker, B. Donnadieu, G. Bertrand, Angew. Chem. 2008, 120, 6382-6385; Angew. Chem. Int. Ed. 2008, 47, 5411-5414.

[2] a) M. Christl, B. Engels, Angew. Chem. 2009, 121, 1566-1567; Angew. Chem. Int. Ed. 2009, 48, 1539-1540; b) V. Lavallo, C. A. Dyker, B. Donnadieu, G. Bertrand, Angew. Chem. 2009, 121, 1568-1570; Angew. Chem. Int. Ed. 2009. $48,1540-1542$

[3] Modern Allene Chemistry (Eds.: N. Krause, A. S. K. Hashmi), Wiley-VCH, Weinheim, 2004.

[4] a) P. W. Dillon, G. R. Underwood, J. Am. Chem. Soc. 1974, 96, 779-787; b) R. O. Angus Jr., M. W. Schmidt, R. P. Johnson, J. Am. Chem. Soc. 1985, 107, 532-537; c) R. P. Johnson, Chem. Rev. 1989, 89, 1111-1124.

[5] This structure, alike 1', and 5', can also be expressed as a resonance between two localized, zwitterionic, Lewis-formula i.e. $\mathrm{C}^{+}-\mathrm{C}^{-}=\mathrm{C} \leftrightarrow$ $\mathrm{C}=\mathrm{C}^{-}-\mathrm{C}^{+}$.

[6] a) B. Silvi, A. Savin, Nature 1994, 371, 683-686; b) A. Savin, A. D. Becke, J. Flad, R. Nesper, H. Preuss, H. G. Schnering, Angew. Chem. 1991, 103, 421424; Angew. Chem., Int. Ed. Engl. 1991, 30, 409-412; c) A. Savin, R. Nesper, S. Wengert, T. F. Fässler, Angew. Chem. 1997, 109, 1892-1918; Angew. Chem., Int. Ed. Engl. 1997, 36, 1809-1832.

[7] We note that no SCF instabilities were found in any of the calculations performed for 2a indicating that density functional theory gives an appropriate description of the electronic structure throughout the range of bond angles employed.

[8] a) F. W. Biegler-Koenig, T. T. Nguyen-Dang, Y. Tal, R. F. W. Bader, A. J. Duke, J. Phys. B: At. Mol. Phys. 1981, 14, 2739-2751; b) R. F. W. Bader, T. T. Nguyen-Dang, Adv. Quantum Chem. 1981, 14, 63-124.

[9] K. J. Daoust, S. M. Hernandez, K. M. Konrad, I. D. Mackie, J. Winstanley, R. P. Johnson, J. Org. Chem. 2006, 71, 5708-5714.

[10] T. Takabe, M. Takahashi, H. Fukutome, Prog. Theor. Phys. 1976, 56, 349360.

[11] a) P. v. R. Schleyer, C. Maerker, A. Dransfeld, H. Jiao, N. J. van Eikema Hommes, J. Am. Chem. Soc. 1996, 118, 6317-6318; b) Z. Chen, C. S. Wannere, C. Corminboef, R. Puchta, P. v. R. Schleyer, Chem. Rev. 2005, 105, 3842-3888; c) H. Fallah-Bagher-Shaidaei, C. S. Wannere, C. Corminboeuf, R. Puchta, P. v. R. Schleyer, Org. Lett. 2006, 8, 863-866.

[12] IUPAC. Compendium of Chemical Terminology, 2nd ed. (the "Gold Book"). Compiled by A. D. McNaught and A.Wilkinson. Blackwell Scientific Publications, Oxford (1997). XML on-line corrected version: 
http://goldbook.iupac.org (2006-) created by M. Nic, J. Jirat, B. Kosata; updates compiled by A. Jenkins.

[13] a) A. E. Reed, F. J. Weinhold, Chem. Phys. 1983, 78, 4066-4073; b) A. E. Reed, R. B. Weinstock, F. J. Weinhod, J. Chem. Phys. 1985, 83, 735-746; c) J. P. Foster, F. J. Weinhold, J. Am. Chem. Soc. 1980, 102, 7211-7218; d) A. E. Reed, L. A. Curtiss, F. J. Weinhold, Chem. Rev. 1988, 88, 899-926.

[14] We note that natural resonance theory (NRT) analysis ${ }^{[1]}$ of 1a using 1" as the leading structure gives smaller weight factors that a similar analysis employing $\mathrm{C}^{+}-\mathrm{C}^{-}=\mathrm{C}$ type resonance structures.

[15] a) W. A. Herrmann, C. Köcher, Angew. Chem. 1997, 109, 2257-2282; Angew. Chem., Int. Ed. Engl. 1997, 36, 2162-2187; b) O. Kühl, Chem. Soc. Rev. 2007, 36, 592-604; c) N-Heterocyclic Carbenes in Synthesis (Ed.: S. P. Nolan), Wiley-VCH, Weinheim, 2006.

[16] a) R. Tonner, G. Frenking, Angew. Chem. 2007, 119, 8850-8853; Angew. Chem. Int. Ed. 2007, 46, 8695-8698; b) R. Tonner, G. Frenking, Chem. Eur. J. 2008, 14, 3260-3272; c) R. Tonner, G. Frenking, Chem. Eur. J. 2008, 14, 3272-3289.

[17] C. A. Dyker, V. Lavallo, B. Donnadieu, G. Bertrand, Angew. Chem. 2008, 120, 3250-3253; Angew. Chem. Int. Ed. 2008, 47, 3206-3209.

[18] O. Kaufhold, F. E. Hahn, Angew. Chem. 2008, 120, 4122-4126; Angew. Chem. Int. Ed. 2008, 47, 4057-4061.

[19] M. M. Deshmukh, S. R. Gadre, R. Tonner, G. Frenking, Phys. Chem. Chem. Phys. 2008, 10, 2298-2301.

[20] In contrast, the NBO analysis predicts an allene Lewis structure for carbodicarbenes. ${ }^{[16]}$ However, as our calculations show, the NBO method describes the parent allene 2a with the traditional Lewis structure irrespective of the bond angle. In fact, the total residual (non-Lewis) density in $\mathbf{2 a}$ drops off slightly as the bond angle is decreased from 180 to $110^{\circ}$. This indicates that the allene Lewis formula should be a better description of the electric structure at bent geometries than at the linear minimum! Clearly the NBO method artificially favors allene-type Lewis structures to a point in which the results become chemically meaningless. However, it was noted earlier that NBO calculations with enforced lone pair orbitals at the central carbon yields only moderately higher residual densities for carbodicarbenes. ${ }^{[16]}$ Hence, a simple remedy to the problem would be to use NRT based analysis. ${ }^{[21]}$

[21] a) S. Feldgus, C. R. Landis, E. D. Glendening, F. Weinhold, J. Comp. Chem. 1998, 21, 411-413; b) E. D. Glendening, F. Weinhold, J. Comp. Chem. 1998, $21,610-627$; c) E. D. Glendening, J. K. Badenhoop, F. Weinhold, J. Comp. Chem. 1998, 21, 628-646.

[22] The same applies to tetraaminoallenes which, despite of their linear geometry as isolated species, can act as four-electron donors towards stronger electrophiles. ${ }^{[16]}$

[23] a) F. Ramirez, N. B. Desai, B. Hansen, N. McKelvie, J. Am. Chem. Soc. 1961, 83, 3539-3540; b) O. Gasser, H. Schmidbaur, J. Am. Chem. Soc. 1975, 97, 6281-6282; c) M. S. Hussain, H. Schmidbaur, Z. Naturforsch. B 1976, 31, 721-726; d) H. Schmidbaur, O. Gasser, M. S. Hussain, Chem. Ber. 1977, 110, 3501-3507; e) A. T. Vincent, P. J. Wheatley, J. Chem. Soc. Dalton Trans. 1972, 617-622; f) E. A. V. Ebsworth, T. E. Fraser, D.W. H. Rankin, O. Gasser, H. Schmidbaur, Chem. Ber. 1977, 110, 3508-3516; f) G. E. Hardy, J.
I. Zink, W. C. Kaska, J. C. Baldwin, J. Am. Chem. Soc. 1978, 100, 80018002; g) H. Schmidbaur, G. Haßlberger, U. Deschler, U. Schubert, C. Kappenstein, A. Frank, Angew. Chem. 1979, 91, 437-438; Angew. Chem. Int. Ed. Engl. 1979, 18, 408-409.

[24] a) R. Tonner, F. Öxler, B. Neumüller, W. Petz, G. Frenking, Angew. Chem. 2006, 118, 8206-8211; Angew. Chem. Int. Ed. 2006, 45, 8038-8042; b) H. Schmidbaur, Angew. Chem. 2007, 119, 3042- 3043; Angew. Chem. Int. Ed. 2007, 46, 2984-2985; c) G. Frenking, B. Neumüller, W. Petz, R. Tonner, F. Öxler, Angew. Chem. 2007, 119, 3044-3045; Angew. Chem. Int. Ed. 2007, 46, 2986-2987.

[25] H. M. Tuononen, R. Roesler, J. L. Dutton, P. J. Ragogna, Inorg. Chem. 2007, 46, 10693-10706.

[26] a) F. Ettel, G. Huttner, L. Zsolnai, L. Angew. Chem. 1989, 101, 1525-1527; Angew. Chem., Int. Ed. Engl. 1989, 28, 1496-1498; b) F. Ettel, G. Huttner, W. Imhof, J. Organomet. Chem. 1990, 397, 299-307.

[27] a) TURBOMOLE, Program Package for ab initio Electronic Structure Calculations; Version 5.10; Theoretical Chemistry Group, University of Karlsruhe: Karlsruhe, Germany, 2008; b) R. Ahlrichs, R.; M. Bär, M. Häser, H. Horn, C. Kölmel, Chem. Phys. Lett. 1989, 162, 165-169.

[28] Gaussian 03, Revision C.02, M. J. Frisch, G. W. Trucks, H. B. Schlegel, G. E. Scuseria, M. A. Robb, J. R. Cheeseman, J. A. Montgomery, Jr., T. Vreven, K. N. Kudin, J. C. Burant, J. M. Millam, S. S. Iyengar, J. Tomasi, V. Barone, B. Mennucci, M. Cossi, G. Scalmani, N. Rega, G. A. Petersson, H. Nakatsuji, M. Hada, M. Ehara, K. Toyota, R. Fukuda, J. Hasegawa, M. Ishida, T. Nakajima, Y. Honda, O. Kitao, H. Nakai, M. Klene, X. Li, J. E. Knox, H. P. Hratchian, J. B. Cross, V. Bakken, C. Adamo, J. Jaramillo, R. Gomperts, R. E. Stratmann, O. Yazyev, A. J. Austin, R. Cammi, C. Pomelli, J. W. Ochterski, P. Y. Ayala, K. Morokuma, G. A. Voth, P. Salvador, J. J. Dannenberg, V. G. Zakrzewski, S. Dapprich, A. D. Daniels, M. C. Strain, O. Farkas, D. K. Malick, A. D Rabuck, K. Raghavachari, J. B. Foresman, J. V. Ortiz, Q. Cui, A. G. Baboul, S. Clifford, J. Cioslowski, B. B. Stefanov, G. Liu, A. Liashenko, P. Piskorz, I. Komaromi, R. L. Martin, D. J. Fox, T. Keith, M. A. Al-Laham, C. Y. Peng, A Nanayakkara, M. Challacombe, P. M. W. Gill, B. Johnson, W. Chen, M. W. Wong, C. Gonzalez, J. A. Pople, Gaussian, Inc., Wallingford CT, 2004.

[29] a) A. D. Becke, J. Chem. Phys. 1993, 98, 5648-5652; b) C. Lee, W. Yang, R. G. Parr, Phys. Rev. B 1988, 37, 785-789; c) S. H. Vosko, L. Wilk, M. Nusair, Can. J. Phys. 1980, 58, 1200-1211; d) P. J. Stephens, F. J. Devlin, C. F. Chabalowski, M. J. Frisch, J. Phys. Chem. 1994, 98, 11623-11627.

[30] F. Weigend, R. Ahlrichs, Phys. Chem. Chem. Phys. 2005, 7, 3297-3305.

[31] S. Noury, X. Krokidis, F. Fuster, B. Silvi, TopMoD, Universite Pierre et Marie Curie, Paris, France, 1997.

[32] R. W. F. Bader, P. Krugg, AIMPAC, Department of Chemistry, McMaster University, Hamilton, ON, Canada, 1990.

[33] E. D. Glendening, J. K. Badenhoop, A. E. Reed, J. E. Carpenter, J. A. Bohmann, C. M. Morales, F. Weinhold, NBO 5.G, Theoretical Chemistry Institute, University of Wisconsin, Madison, WI, 2001.

[34] a) L. Laaksonen, J. Mol. Graph. 1992, 10, 33-34; b) D. L. Bergman, L. Laaksonen, A. Laaksonen, J. Mol. Graph. Model. 1997, 15, 301-306. 